\title{
The consistency of Arsenic's high value regions in surface and bottom waters in Jiaozhou Bay
}

\author{
Dongfang Yang ${ }^{1,2,3},{ }^{*}$, Jianxun Chai ${ }^{1,2}$, Xiaoye $\mathrm{Gao}^{1,2}$, Yunjie $\mathrm{Wu}^{1,2}$, and Sixi $\mathrm{Zhu}^{1,2}$ \\ ${ }^{1}$ Research Center for Karst Wetland Ecology, Guizhou Minzu University, Guizhou Guiyang, Guizhou Guiyang, China \\ ${ }^{2}$ College of Chemistry and Environmental Science, Guizhou Minzu University, Shanghai, 550025, China \\ ${ }^{3}$ North China Sea Environmental Monitoring Center, SOA, Qingdao 266033, China
}

\begin{abstract}
This paper analyzed the contents and distributions of As in Jiaozhou Bay in 1982. Results showed that As's contents in bottom waters in coastal waters in the southwest of the bay and the bay mouth in Jiaozhou Bay in July and October 1982 were 0.88-4.48 $\mu \mathrm{g} \mathrm{L}^{-1}$ and 0.84-1.16 $\mu \mathrm{g} \mathrm{L}^{-1}$, respectively. As's contents were much lower than the guide line of Grade I, and the pollution level of As in bottom waters in Jiaozhou Bay in 1982 was still very slight. There was high value region in coastal waters in the southwest of the bay in July $1982\left(4.48 \mu \mathrm{g} \mathrm{L}^{-1}\right)$, while in October 1982 high value region was in the bay mouth $(1.16 \mu \mathrm{g}$ $\left.\mathrm{L}^{-1}\right)$. The source input of As from overland runoff in the southwest was strong in July, resulted in relative high value region in surface waters in coastal waters in the southwest of the bay, and therefore resulted in high value region in bottom waters in same region by means of rapid sedimentation of As. October was wet season and there was little As input to the bay, resulted in low As's contents in surface waters, as well as bottom waters. At any time, the terrigenous As was foremost transported to surface waters, and was subsided to sea bottom through water body by vertical water's effect. Hence, the high value regions of As's contents in surface and bottom waters had characteristic of consistency in Jiaozhou Bay.
\end{abstract}

\section{Introduction}

As is one of the widely used elements in industry and agriculture, yet certain form of As such as arsenic trioxide is high toxic. Nowadays, many marine bays have been polluted by As due to the rapid development of economic and population size ([1-2]). Hence, understanding the horizontal distributions and vertical transferring processes of As in marine bays is essential to pollution control ([3-4]). The changes of As's contents were mainly determined bay source input and vertical water's effect, and resulted in the varions of As's distributions in surface and bottom waters ([3-6]).

Jiaozhou Bay is a semi-closed bay located in Shandong Province China, and has been polluted by various pollutants including As since China's Reform and Opening-up ([1-2]). This paper the anzlyzed contents and distributions of As in Jiaozhou Bay in 1982. Results found that the terrigenous As was foremost transported to surface waters, and was subsided to sea bottom through water body by vertical water's effect. The high value regions of As's contents in surface and bottom waters had characteristic of consistency in Jiaozhou Bay. These results were important basis for scientific research and environment management decision-making.

\subsection{Study area}

Jiaozhou Bay is located in the south of Shandong Province, eastern China $\left(35^{\circ} 55^{\prime}-36^{\circ} 18^{\prime} \mathrm{N}, 120^{\circ} 04^{\prime}\right.$ $\left.120^{\circ} 23^{\prime} \mathrm{E}\right)$. The total area, average water depth and the width of the bay mouth are $446 \mathrm{~km} 2,7 \mathrm{~m}$ and $3 \mathrm{~km}$, respectively. The bay mouth is connecting to the Yellow Sea in the south, and is surrounded by Qingdao, Jiaozhou and Jiaonan in the east, north and west, respectively (Fig. 1). There are a dozen of rivers, all of which are seasonal rivers ([7-8]).

\subsection{Data collection}

The investigation on As in surface waters in Jiaozhou Bay was carried on in July and October 1982 in four sampling sites (i.e., 083, 084, 122 and 123) (Fig. 1). As in waters was sampled and monitored follow by National Specification for Marine Monitoring ([9]).

\section{Materials and method}

\footnotetext{
* Corresponding author: dfyang_dfyang@126.com
} 


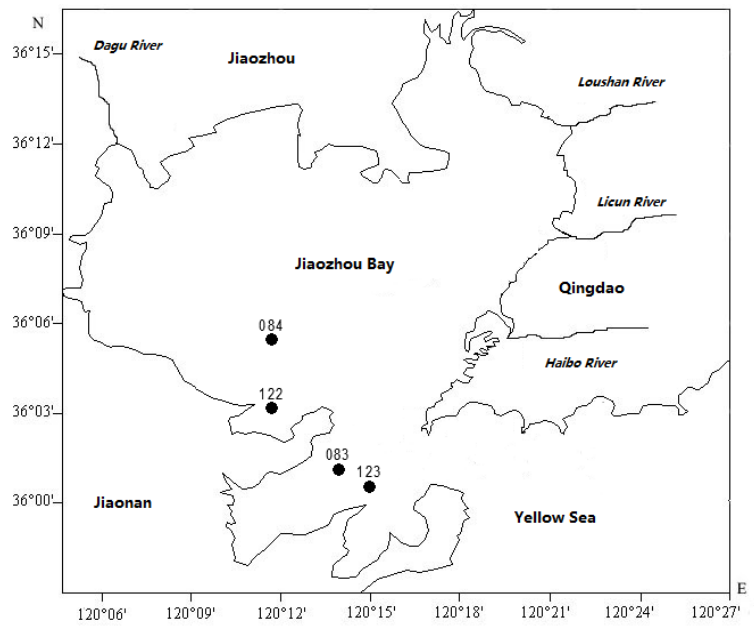

Fig. 1. Geographic location and monitoring sites in Jiaozhou Bay.

\section{Results}

\subsection{Contents and pollution level of As in bottom waters}

As's contents in bottom waters in coastal waters in the southwest of the bay and the bay mouth in Jiaozhou Bay in July and October 1982 were $0.88-4.48 \mu \mathrm{g} \mathrm{L}^{-1}$ and 0.84-1.16 $\mu \mathrm{g} \mathrm{L}^{-1}$, respectively. In according to Sea Water Quality Standard (GB 3097-1997) for As, As's contents were much lower than the guide line of Grade I for As (20.00 $\left.\mu \mathrm{g} \mathrm{L}^{-1}\right)$. In general, the pollution level of As in bottom waters in Jiaozhou Bay in 1982 was still very slight (Table 1).

Table 1. Contents and pollution level of As in bottom waters in Jiaozhou Bay 1982

\begin{tabular}{|c|c|c|}
\hline & July & October \\
\hline $\begin{array}{c}\text { Content } / \mu \mathrm{g} \mathrm{L} \\
1\end{array}$ & $0.88-4.48$ & $0.84-1.16$ \\
\hline Grade & $\mathrm{I}$ & $\mathrm{I}$ \\
\hline
\end{tabular}

\subsection{Horizontal distributions of As in bottom waters}

In July 1982, high value of As's contents was in Site 084 in coastal waters in the southwest of the bay, and the countour lines of As's contents were forming a series of parallel lines that decreasing from the coastal waters in the southwest of the bay $\left(4.48 \mu \mathrm{g} \mathrm{L}^{-1}\right)$ to the bay mouth $\left(0.88 \mu \mathrm{g} \mathrm{L}^{-1}\right)$ (Fig. 2). In October 1982, high value of As's contents was in Site 123 in the bay mouth, and the countour lines of As's contents were forming a series of semi-circles that decreasing from the bay mouth $(1.16 \mu \mathrm{g}$ $\left.\mathrm{L}^{-1}\right)$ to the coastal waters in the southwest of the bay (0.84 $\left.\mu \mathrm{g} \mathrm{L}^{-1}\right)$ (Fig. 3).

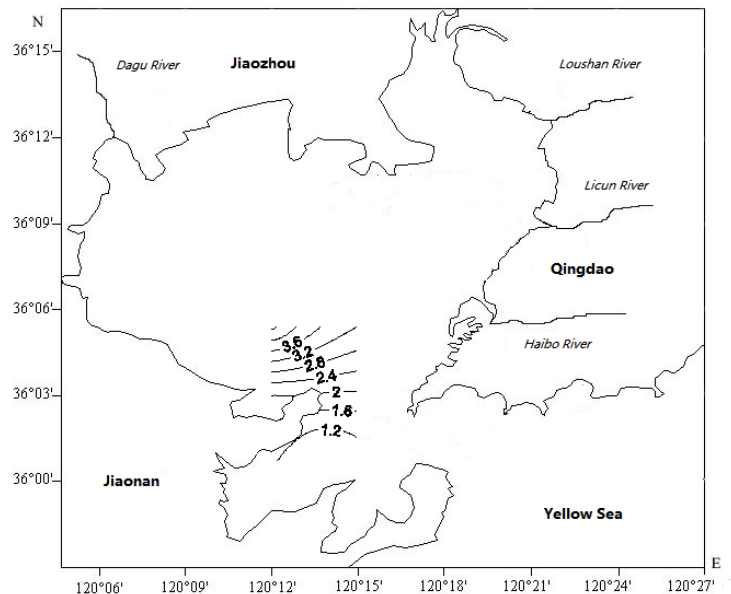

Fig. 2. Horizontal distribution of As in bottom water in Jiaozhou Bay in July 1982/ $\mathrm{g} \mathrm{L}^{-1}$

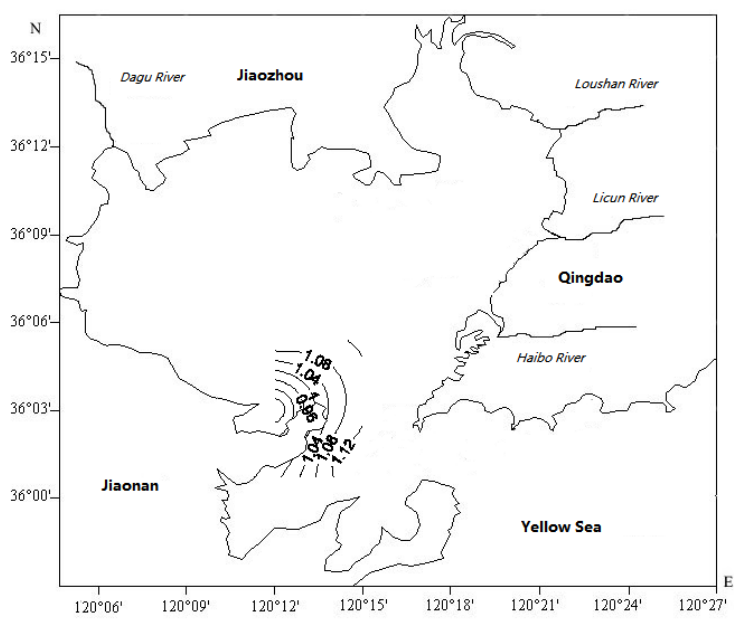

Fig. 3. Horizontal distribution of As in bottom water in Jiaozhou Bay in October 1982/ $\mu \mathrm{g} \mathrm{L} \mathrm{L}^{-1}$

\section{Discussion}

\subsection{High sedimentation regions of As}

In July 1982, As contents were decreasing from the southwest of the bay to the bay mouth, indicated that high sedimentation process was occurring in coastal waters in the southwest of the bay $\left(4.48 \mu \mathrm{g} \mathrm{L}^{-1}\right)$. In October 1982, As contents were decreasing from the bay mouth to the southwest of the bay, indicated that high sedimentation process was occurringin the bay mouth $\left(1.16 \mu \mathrm{g} \mathrm{L}^{-1}\right)$. The sedimentation strength in coastal waters was much stronger than in the bay mouth. At any time, the terrigenous As was foremost transported to surface waters, and was subsided to sea bottom through water body by vertical water's effect ([4-5], ([10])). The horizontal distributions of As's contents were determined by source input and vertical water's effect.

\subsection{Transferring processes of As}

The horizontal distribution of As's contents in surface waters in July 1982 showed that As's contents were 
decreasing from the coastal waters in the southwest to the bay mouth, and indicated that overland runoff was the major source. Hence, there was high value region of As's contents in surface waters in coastal waters in southwest of the bay, and by means of vertical water's effect ([4-5]), As was transferred to and accumulated in bottom layer of waters, resulted in high value region in bottom waters in this area. The horizontal distribution of As's contents in surface waters in October 1982 showed that As's contents were showing no trends but disorder patches, and therefore indicated that there was little souce input. Hence, there was no high value region of As's contents in surface waters in the bay, nor high value region in bottom waters in this area. However, in case of relative strong source input, there was high value regions in surface waters, as well as in bottom waters, and the high value regions had characteristic of consistency by means of vertical water's effect.

\section{Conclusions}

As's contents in bottom waters in coastal waters in the southwest of the bay and the bay mouth in Jiaozhou Bay in July and October 1982 were $0.88-4.48 \mu \mathrm{g} \mathrm{L}^{-1}$ and 0.84-1.16 $\mu \mathrm{g} \mathrm{L}^{-1}$, respectively. As's contents were much lower than the guide line of Grade I, and the pollution level of As in bottom waters in Jiaozhou Bay in 1982 was still very slight. The horizontal distributions of As's contents were determined by source input and vertical water's effect. In case of relative strong source input, there was high value regions in surface waters, as well as in bottom waters, and the high value regions had characteristic of consistency by means of vertical water's effect.

\section{Acknowledgments}

This research was sponsored by Research Projects of Guizhou Nationalities University ([2014]02), Research Projects of Guizhou Province Ministry of Education (KY [2014] 266), Research Projects of Guizhou Province Ministry of Science and Technology (LH [2014] 7376).

\section{References}

1. D.F. Yang, W.P. Song, S.T. Chen, J.H. Guo, L. Zheng, Coastal Engineering, 31, 4(2012)

2. D.F. Yang, Y.H. Zhao, Z.G. Piao, Ocean Development and Management, 31, (2014)

3. D.F. Yang, S.X. Zhu, F.Y. Wang, S.T. Chen, Z.J. $\mathrm{Xu}$, S.X. Zhu, Y.J. Wu, Meterological and Environmental Research, 5, (2014)

4. D.F. Yang, F.Y. Wang, H.Z. He, Y.J. Wu, S.X. Zhu, Proceedings of the 2015 international symposium on computers and informatics, (2015)

5. D.F. Yang, F.Y. Wang, X.L. ZhaoY.J. Wu, S.X. Zhu, Sustainable Energy and Enviroment Protection, (2015)
6. D.F. Yang, F.Y. Wang, X.Q. Yang, Y.J. Wu, S.X. Zhu, Advances in Computer Science Research, 3252, (2015)

7. D.F. Yang, Y. Chen, Z.H. Gao, J. Zhang, F. Wang, Chinese Journal of Oceanology and Limnology, 23, 1(2005)

8. D.F. Yang, F.Y. Wang, Z.H. Gao, W.L. Cui, S.X. Huo, Marine Science, 28, 6(2004)

9. China's State Oceanic Administration, The specification for marine monitoring (Ocean Press, Beijiang, 1991)

10. Yang DF, Miao ZQ, Xu HZ, Y. Chen, J.Y. Sun, Marine Environmental Science, 32, 3(2013) 